\title{
PENINGKATAN PENDAPATAN UKM MELALUI PENGUASAAN TEKNOLOGI PAKAN LELE DAN PEMANFAATAN LIMBAH LOKAL DESA JATISARI KECAMATAN JATISRONO, KABUPATEN WONOGIRI
}

\author{
Rochmi Widayanti ${ }^{1}$, Endang Masitoh, Sudarwati \\ Fakultas Ekonomi \\ Universitas Islam Batik Surakarta \\ Email ${ }^{1}$ : rochmiwidayanti@gmail.com
}

\begin{abstract}
IbM activities carried out in the village Jatisari, local village government has formed groups of fish farmers, but due to constraints in the high feed costs, the number of farmers began to decrease from 20 to less than 5 people catfish farmers. Constraints, high feed costs caused by dependence on the feed manufacturers and fish farmers group is limited knowledge about the creation of alternative feed. Limitations in managing the business also experienced group of fish farmers, especially in production planning and financial of the business, through the program IbM, expected these problems can be finished.

The IbM program consist of:(1)business management training (business plan), (2) training of feed manufacturing catfish with the use of local waste and can be as alternative feed, (3) training on mastery of engine technology prill fish pellets simple and integrated with dryers that can be used as an alternative to the rainy season. Outcomes of this program can be formed business group catfish farmers are independent, able to manage the business properly, can make alternative feed and capable of implementing the technology.
\end{abstract}

Kata kunci: perencanaan bisnis, teknologi pakan, limbah lokal

\section{PENDAHULUAN}

Jatisari adalah desa di Kecamatan Jatisrono berjarak $32 \mathrm{~km}$ dari Ibu Kota Kabupaten Wonogiri. Wilayah kerja pertanian Kecamatan Jatisrono terdiri dari 15 desa dan 2 kelurahan dengan luas wilayah keseluruhan 5.002,7360 Ha. Penggunaan lahan dengan memperhatikan jenis lahan dan topografi yang bergelombang sedikit miring, dimana untuk lahan sawah merupakan tempat untuk bercocok tanam padi sawah berpengairan teknis $84,8106 \mathrm{Ha}$, berpengairan $1 / 2$ teknis 525,4967 Ha dan 814,521 Ha untuk bercocok tanam padi tadah hujan dan sebagian lainnya ditanami jenis sayuran. Desa Jatisari merupakan salah satu desa yang memiliki banyak potensi untuk dikembangkan.
Pemerintah desa setempat mengembangkan dari sektor pertanian dan perikanan.

Usaha perikanan, khususnya ternak lele, sebelumnya cukup banyak peminatnya karena kebutuhan pasar yang tinggi terhadap permintaan ikan lele. Namun, saat ini mulai berkurang yang disebabkan oleh biaya pakan yang tinggi dan penduduk belum mampu membuat dengan memanfaatkan teknologi. Selama ini pakan pelet dibeli dengan harga yang cukup mahal, sehingga ongkos produksi juga cukup tinggi. Karena biaya pakan yang tinggi, banyak kolam ikan yang mangkrak dalam artian tidak digunakan lagi untuk kolam ikan lele dan dibiarkan rusak. Secara ringkas permasalahan dari mitra IbM ditunujukkan dalam tabel 1, berikut ini: 
Tabel 1. Permasalahan Mitra Kelompok Usaha Kecil di Jatisari

\begin{tabular}{|c|c|c|}
\hline & Kelompok Tani Ternak "Sidomulyo" & Kelompok Pemuda Kreatif "LKMPP" \\
\hline 1. & $\begin{array}{l}\text { Terbatasnya pengetahuan tentang manajemen } \\
\text { usaha sehingga usaha yang dilakukan sering } \\
\text { gagal karena tidak ada perencanaan atau } \\
\text { business plan } \\
\text { Tingginya ongkos pakan ikan karena } \\
\text { ketergantungan yang tinggi pada pakan pelet } \\
\text { pabrik }\end{array}$ & $\begin{array}{l}\text { 1. Kesulitan dalam melakukan perencanaan } \\
\text { usaha, khususnya dalam merencanakan biaya } \\
\text { produksi yang efisien, masih mendasarkan } \\
\text { pada coba-coba } \\
\text { 2. Masih menggunakan pakan pelet pabrik, } \\
\text { namun sudah mencoba mengkombinasikan } \\
\text { dengan fermentasi }\end{array}$ \\
\hline 3. & $\begin{array}{l}\text { Ketergantungan pada pakan pelet pabrik } \\
\text { sehingga enggan mengenal teknologi pakan } \\
\text { pelet ikan }\end{array}$ & $\begin{array}{l}\text { 3. Kurangnya pengetahuan tentang } \\
\text { pemanfaatan limbah lokal untuk alternatif } \\
\text { makana ikan }\end{array}$ \\
\hline 4. & $\begin{array}{l}\text { Terbatasnya pengetahuan tentang } \\
\text { pemanfaatan limbah lokal yang berasal dari } \\
\text { pertanian dan peternakan yang berguna bagi } \\
\text { pakan ikan. } \\
\text { Kurangnya pemahaman tentang pentingnya } \\
\text { tata kelola keuangan usaha dan pemisahan } \\
\text { keuangan pribadi bdengan usaha } \\
\text { Pemasaran hasil ikan dijual masih sebatas } \\
\text { lingkungan lokal atau lingkup desa Jatisari } \\
\text { karena hasil usaha budidaya ikan masih } \\
\text { terbatas. }\end{array}$ & $\begin{array}{l}\text { 4. Keterbatasan dalam penguasaan teknologi } \\
\text { pembuatan pakan pelet ikan dan kendala } \\
\text { ketersediaan pakan pada musim penghujan. } \\
\text { 5. Masih sedikit yang mengenal pengelolaan } \\
\text { keuangan, belum ada pemisahan keuangan } \\
\text { usaha dengan uang pribadi. } \\
\text { 6. Hasil ikan dipasarkan lingkup lokal dan } \\
\text { untuk konsumsi pribadi dan belum mengenal } \\
\text { differensiasi produk. }\end{array}$ \\
\hline
\end{tabular}

\section{METODE PELAKSANAAN}

\section{Metode Pendekatan}

Pelaksanaan program ipteks bagi masyarakat $\mathrm{I}_{\mathrm{b}} \mathrm{M}$ dilakukan dengan menggunakan pendekatan edukasi yang berupa pemberian pelatihan kecakapan hidup (life skill) kepada kelompok mitra yaitu kelompok tani ternak "Sidomulyo" dan kelompok pemuda kreatif "LKMPP". Pendidikan kecakapan hidup mencakup empat aspek yaitu: kecakapan personal, kecakapan sosial, kecakapan akademik, kecakapan vokasional.

Kegiatan pada program pengabdian masyarakat ini menyentuh pada konsep usaha kecil, namun tidak menutup kemungkinan akan memunculkan usaha kecil yang berkembang menjadi sebuah perusahaan. Sehingga arah keberlanjutan agar dapat menjadikan usaha kecil sebagai perusahaan, maka diperlukan 5 (lima) aspek yang harus dicermati yaitu: aspek produksi dan teknologi, aspek pemasaran, aspek keuangan, aspek manajemen dan aspek sumber daya manusia (SDM) yang harus dimiliki kelompok mitra.

\section{Prosedur Kerja}

Melalui kegiatan $\mathrm{I}_{\mathrm{b}} \mathrm{M}$ ini, akan ditawarkan solusi bagi permasalahanpermasalahan yang telah disepakati menjadi prioritas utama untuk diselesaikan. Sebagai upaya mendukung realisasi pelaksanaan program $\mathrm{I}_{\mathrm{b}} \mathrm{M}$ dalam bentuk pelatihan dan penerapan Ipteks, prosedur yang dilalui meliputi beberapa tahapan berikut:

\section{Tahap Persiapan;}

Pada tahap ini, diawali brainstorming dan menyamakan persepsi dalam 1 (satu) tim pengabdian masyarakat, sosialisasi rencana kegiatan dengan pemerintah desa Jatisari dan kelompok mitra di desa Jatisari, dan mengurus perijinan pada dinas terkait. Hal ini dilakukan sebagai upaya pematangan program dan persiapan dari kelompok mitra dalam berperan aktif mendukung pelaksanaan program $\mathrm{I}_{\mathrm{b}} \mathrm{M}$

2. Tahap Pengkajian/Assesment;

Tahapan selanjutnya adalah mengkaji permasalahan yang disepakati untuk diselesaikan sesuai dengan program kegiatan, kelayakan tujuan program dengan kemampuan sumber daya yang dimiliki 
(SDM), pengkajian tim pelaksana dan keselarasan kompetensi tim ahli (pakar) yang sesuai dengan kegiatan pelatihan.

3. Tahap Perencanaan Program

Tahap ini dilakukan dengan memformulasikan tujuan yang ingin dicapai setelah dilakukan pengkajian program, perincian atau urutan kegiatan, penanggungjawab program atau personalia masing-masing kegiatan, jadwal pelaksanaan dan membuat indikator pencapaian program dan rencana evaluasi program serta kemungkinan keberlanjutan program.

4. Tahap Pelaksanaan (Implementasi)
Program
Merinci prosedur pelaksanaan program, mengurutkan kegiatan dimulai dari pelaksanaan pelatihan manajemen usaha sampai dengan transfer teknologi dalam pembuatan pakan ikan. Pada tahap ini meliputi pemberian materi pelatihan kecakapan keterampilan bekerja berbasis bidang minat usaha ternak ikan lele dengan sasaran akhir setelah proses pembelajaran selesai adalah kemampuan peserta didik untuk mampu berwirausaha secara mandiri. Program pelatihan berlangsung efektif selama 2 (dua) minggu dengan frekuensi pertemuan 10 (sepuluh) kali. Materi teori diberikan selama 4 (empat) kali tatap muka (35\%) dan materi praktek diberikan selama 6 (enam) kali tatap muka (65\%). Model pembelajaran dilakukan secara klasikal (dengan metode ceramah), tanya jawab dan diskusi, demonstrasi (praktek kerja kelompok), serta studi lapangan (kunjungan langsung pada pengusaha lele yang telah berhasil). Metode pembelajaran yang digunakan adalah metode partisipatoris dengan mendorong peserta didik mengembangkan diri dalam mengenali permasalahan dan secara proaktif mencari pemecahannya.

5. Tahap Evaluasi;

Melaksanakan evaluasi terhadap pelaksanaan program, memastikan program sudah berjalan sesuai dengan perencanaan dan tujuan, serta efektivitas dari pelaksanaan program kegiatan ipteks bagi masyarakat $\left(\mathrm{I}_{\mathrm{b}} \mathrm{M}\right)$.
6. Tahap Terminasi.

Pada tahap ini penyelesaian program sesuai dengan kontrak dari kegiatan ipteks bagi masyarakat $\left(\mathrm{I}_{\mathrm{b}} \mathrm{M}\right)$, pada tahap ini diharapkan kelompok usaha ternak ikan sudah mampu mandiri dan dapat menerapkan secara aplikatif apa yang diperoleh selama kegiatan berlangsung. Namun, untuk menjaga keberlanjutan program, tetap dilakukan pendampingan agar ke depan kelompok ini dapat maju dan berkembang merambah ke arah produk ekspor d a $\mathrm{r}$ i hasil panen menjadi produk inovatif

\section{HASIL DAN PEMBAHASAN}

Program Ipteks bagi Masyarakat (IbM) merupakan salah satu kegiatan yang didanai oleh kemenristekdikti sebagai upaya dalam menyalurkan ilmu pengetahuan dan teknologi dengan tujuan peningkatan kesejahteraan pada masyarakat. Kegiatan dalam IbM ini, memfokuskan pada kelompok peternak ikan lele yang ada di desa Jatisari kecamatan Jatisrono kabupaten Wonogiri.

Salah satu upaya dalam menyelesaikan permasalahan yang dihadapi kelompok peternak, maka tim pengabdian masyarakat IbM ini menghasilkan beberapa kegiatan sebagai berikut:

\section{Perijinan Pengabdian Masyarakat (IbM)}

Pada tahapan ini, sebelum kegiatan pengabdian masyarakat (IbM) dilaksanakan di desa Jatisari Wonogiri, Tim Pengabdian masyarakat melakukan proses perijinan ke Pemerintah Kabupaten Wonogiri bidang Kesatuan Bangsa dan Politik pada tanggal 18 Maret 2016. Selanjutnya setelah disetujui berkas dibawa ke Bupati Wonogiri, Camat Jatisrono, dan yang terakhir pada pemerintah desa (Kepala Desa Jatisrono) Bp. Teguh Subroto.

\section{Brainstorming Tim dan Sosialisasi Program}

Kegiatan Ipteks bagi Masyarakat (IbM) merupakan kegiatan pengabdian yang dilaksanakan oleh pihak tim pengabdian UNIBA Surakarta dan juga dari dukungan pemerintah desa, yang dapat dijelaskan secara rinci sebagai berikut: 
a. Tim Pengabdian Masyarakat Universitas Islam Batik Surakarta, yang terdiri dari: 3 dosen dan 2 (dua) praktisi, 4 (empat) mahasiswa dan 1 orang yang bertugas sebagai administrasi.

b. Kelompok Peternak Lele yaitu Kelompok Sidomulyo dan Kelompok Pemuda Tani yang terdiri per kelompok 4 orang (1 ketua dan 3 anggota)

c. Pemerintah Desa yaitu dukungan dari Kepala Desa dan perangkatnya dalam menyediakan tempat pelatihan dan juga alat pendukung pelatihan dalam program IbM ini.

\section{Pelaksanaan Workshop Manajemen Budidaya Lele}

Kegiatan pengabdian masyarakat (IbM) ini mengupayakan adanya pemahaman tentang pengelolaan budidaya ikan lele secara benar, antusias ditunjukkan oleh kelompok ternak ikan dari Jatisari dan juga kepala desa karena menyimak dan mengikuti serta melakukan tanya jawab dengan narasumber atau praktisi dari bidang peternakan ikan lele.

Biaya pakan dalam usaha budidaya ikan dibutuhkan sekitar antara 50-60\% dari total biaya produksi, sehingga perlu adanya upaya untuk meminimalisir biaya tersebut dengan membuat pakan sendiri. Sedangkan keutamaan dalam membuat pakan sendiri dibandingkan pabrik adalah: (1) harga menjadi lebih murah bila dibandingkan dengan harga yang kita beli di toko, (2) selalu dalam keadaan baru, (3) ikut membantu dalam mengurangi pencemaran akibat limbah pabrik. Namun dalam pembuatan pakan pelet lele juga ada poin penting yang harus diperhatikan, yaitu:

a. Pelet harus mudah dicerna oleh ikan.

b. Mempunyai kandungan gizi yang cukup, terutama kandungan proteinnya harus diatas 28-32, selain itu harus juga mengandung lemak, vitamin, mineral, zat kapur dan karbohidrat.

c. Pelet harus mempunyai daya apung serta tidak cepat hancur di air.

d. Pelet harus dapat disimpan dalam jangka waktu yang lama

\section{Praktek Produksi Pembuatan Pakan}

Pelatihan pembuatan pakan lele dilaksanakan dengan narasumber Ir Suryono, MP, dari UNS yang sudah lama bergelut di dunia perikanan, khususnya ikan lele. Pada kegiatan ini sharing pengalaman dengan narasumber terkait budidaya lele dan permasalahan yang dihadapi peternak ikan lele di Jatisari. Setelah selesai diskusi, dilanjutkan dengan praktek pembuatan pakan pelet ikan lele dengan kombinas alternatif bahan limbah di Jatisari:

a. tepung ikan

b. bulu ayam

c. kotoran puyuh/kambing yang sudah dihaluskan

d. Cangkang telur

e. Remukan ikan

f. Minyak ikan (kaldu ikan yang dimasak menjadi minyak ikan)

Selanjutnya, untuk lebih terperinci Ir. Suryono, MP, memberikan urutan pembuatan pakan dengan beberapa bahan alternatif limbah yang dapat digunakan sebagai bahan pembuatan pakan ikan lele, melalui beberapa tahap:
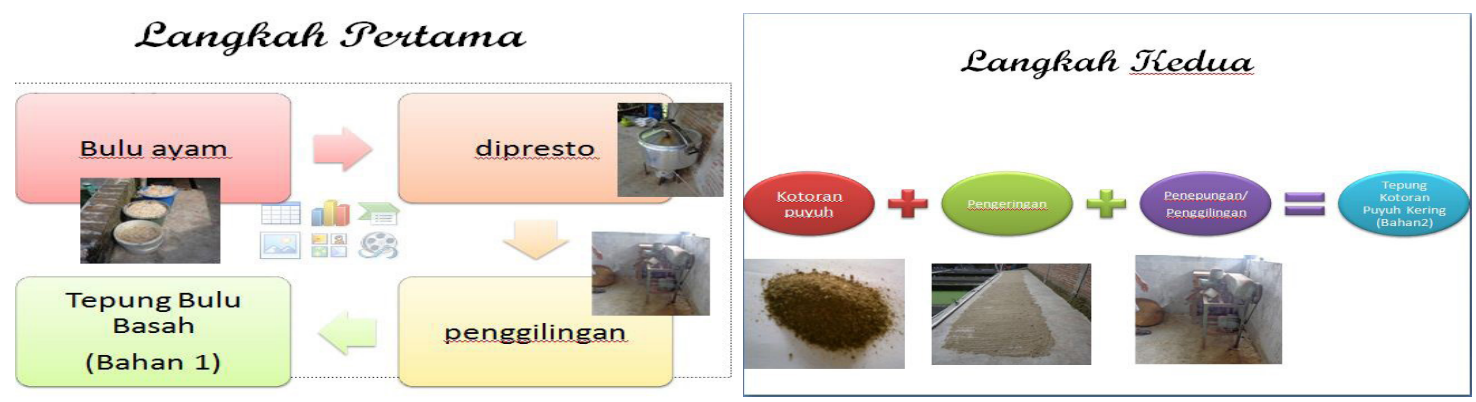


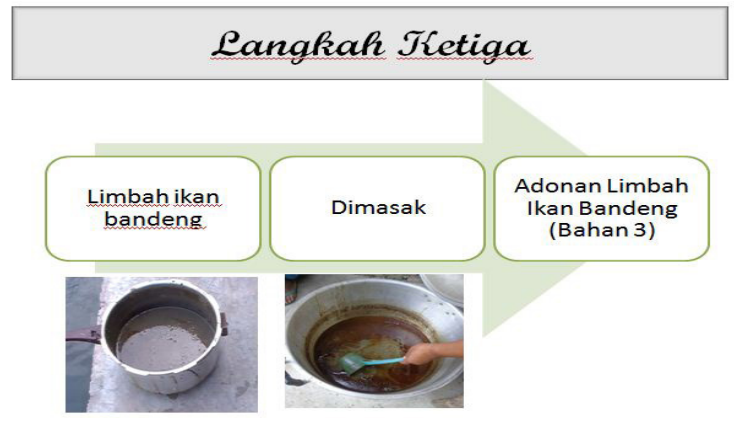

Langkah Thelima
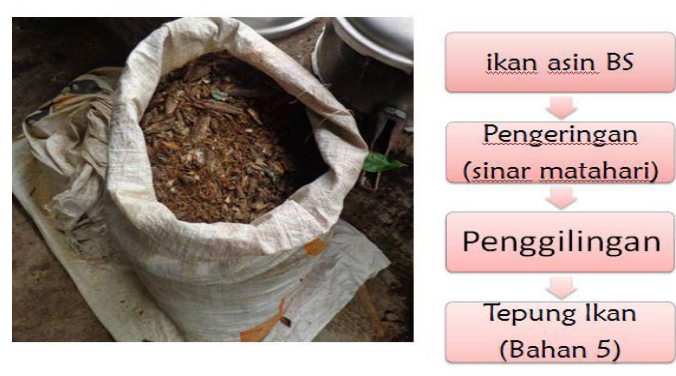

Langkah Thetujuh

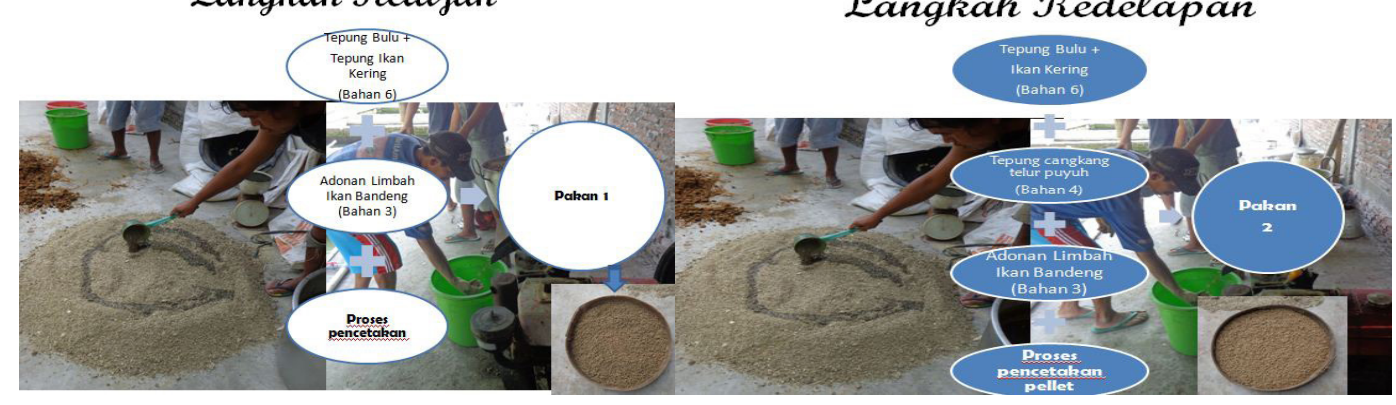

Gambar 1. Proses Pembuatan Prill Pakan Pelet Lele

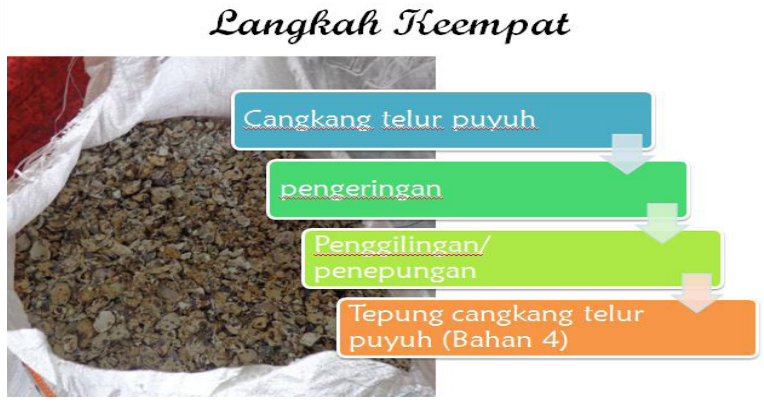

Langkah Theenam

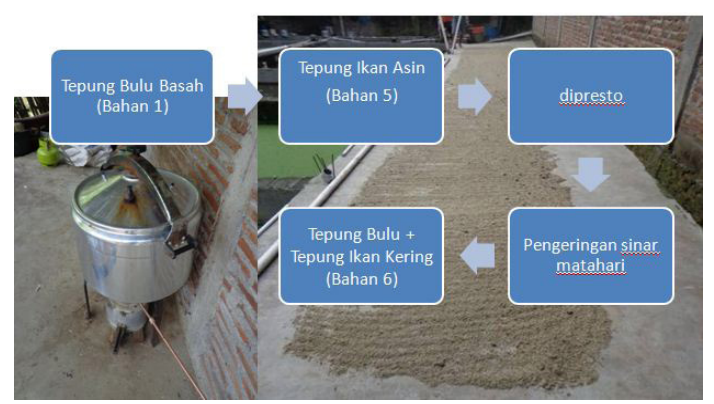

Langkak Thedelapan

a. Wadah /tempat masuk

b. Tempat penggilingan sekaligus pemanas (burner)

c. Pemanas (burner) dengan gas

d. Pemotong yang berada di pintu keluar gilingan

4. Kapasitas $200 \mathrm{~kg} / \mathrm{jam}$ dengan prill ukuran $5 \mathrm{~mm}$

5. Berat Mesin $110 \mathrm{~kg}$

Sedangkan proses pembuatannya dapat dijelaskan sebagai berikut:

a. Menyiapkan terlebih dahulu adonan pakan yang akan digunakan

b. Hidupkan mesin dengan pengerak listrik arus DC sebagai penggerak, mesin bisa juga di gerakkan dengan accu (Aki)/ aki motor dengan ampere yang cukup rendah, fungsinya pengerak tersebut 
dibuat arus DC, masyarakat pedesaan tetap dapat menggunakan ketika listrik dari PLN mati

c. Putaran motor kemudian diatur dengan reducer untuk mengatur kecepatan pengilingan

d. Setelah putaran stabil, masukkan adonan pakan tadi ke dalam penggiling khusus yang telah dimodifikasi, pada tabung pengilingan ini berbeda dengan pengilingan biasa yang mengunakan mesin pengiling daging, karena pada proses pengilingan ini pada ujungnya diberikan pemanas untuk memadatkan serta mengeringkan hasil pakan supaya lebih kering, dan diujung pemanas ini juga ada pemotong hasil adonan hingga menyerupai hasil pakan prill

e. Kekeringan ini akan mengakibatkan pakan menjadi mudah mengapung, sehingga pakan kering dapat di makan semua oleh ikan, dengan hasil olahan pakan bisa habis termakan oleh ikan, yang bertujuan menambah ikan lebih cepat besar dan cepat dipanen

f. Untuk hasil yang maksimal perlu dicoba berulang dari mulai adonan yang mempunyai kadar air, berapa besar dan waktu api yang digunakan pada proses pengeringan pada burner.

g. Setelah selesai penggunaan mesin, matikan mesin penggerak dan bersihkan tempat berlubang dengan air

\section{Kegiatan Penyuluhan dan Pelatihan} Manajemen Usaha

Program IbM ini mempuyai tujuan meningkatkan pengetahuan dan pemahaman dalam kegiatan manajemen usaha. Kegiatan ini meliputi:

1. Motivasi Usaha sebagai langkah menjaga semangat dan komitmen dari kelompok ternak lele di Jatisari dalam mengembangkan usaha termasuk dalam membuat rencana usaha atau analisis usaha, perbaikan produksi, kegiatan marketing, dan juga selalu memisahkan keuangan pribadi dengan keuangan usaha.

2. Pelatihan Pembukuan dengan memberikan analisis kasus yang dihadapi kelompok peternak sesuai dengan kendala yang dihadapi, kelompok belajar praktek pembuatan pencatatatan kas, penerimaaan dan pengeluaran, serta neraca usaha.

Kegiatan IbM ini merupakan program berkelanjutan dengan harapan hasil yang telah dicapai dapat terus dikembangkan, program pendampingan dilakukan juga sebagai sarana peningkatan kerjasama, pengembangan inovasi pakan dan juga kontinuitas usaha kelompok peternak lele di Jatisari.

Tabel 2. Peningkatan setelah kegiatan IbM dilaksanakan

\begin{tabular}{|c|c|}
\hline Sebelum Program IbM & Setelah Program IbM \\
\hline $\begin{array}{l}\text { 1. Ketergantungan pada pakan pabrik } \\
\text { 2. Biaya pakan yang tinggi } \\
\text { 3. Kurangnya pengetahuan tentang manajemen } \\
\text { usaha } \\
\text { 4. Jumlah peternak lele berkurang akibat biaya } \\
\text { pakan tinggi } \\
\text { 6. Motivasi usaha menurun } \\
\text { 6elum menguasai teknologi pakan }\end{array}$ & $\begin{array}{l}\text { 1. Biaya pakan dapat dihemat sampai } \\
\text { dengan } 50 \% \text { disebabkan kelompok } \\
\text { sudah mampu membuat pakan sendiri. } \\
\text { 2. Jumlah peternak lele meningkat } \\
\text { 3. Mampu membuat perencanaan usaha } \\
\text { 4. Melakukan pembukuan sederhana } \\
\text { 5. Mampu mengoperasikan mesin dan } \\
\text { perawatan mesin }\end{array}$ \\
\hline
\end{tabular}

\section{KESIMPULAN DAN SARAN}

\section{Kesimpulan}

Program kegiatan pengabdian masyarakat (IbM) ini memberikan manfaat bagi dunia perguruan tinggi dan masyarakat dalam transfer ilmu pengetahuan dan teknologi. Kegiatan IbM ini mendapatkan dukungan pendanaan dari kemenristekdikti pada tahun 2016, diharapkan mampu membantu masyarakat mitra dalam 
menyelesaikan permasalahan yang dihadapi. Beberapa hal yang dapat disimpulkan dari kegiatan IbM ini sebagai berikut:

1. Kegiatan workshop pengabdian masyarakat ini dengan tema budidaya lele memberikan manfaat ke masyarakat, khususnya kelompok ternak lele di Jatisari, dari kegiatan ini terjadi sharing pengalaman dan permasalahan tentang budidaya lele. Kelompok ternak mendapatkan pengetahuan dan pengalaman baru untuk sarana peningkatan produktivitas hasil ternak ikan lele

2. Kegiatan pelatihan pembuatan pakan memberikan pengalaman ketrampilan untuk dapat membuat sendiri pakan lele dengan menggunakan bahan-bahan lokal yang tersedia di desa Jatisari, sehingga dengan ketrampilan tersebut dapat digunakan untuk mengurangi biaya pakan yang sebelumnya selalu dibeli di pabrik.

3. Melalui program ini terjadi hubungan yang selaras dan manfaat antara perguruan tinggi dengan masyarakat, sehingga dunia perguruan tinggi lebih dapat menjadi fasilitator dan juga media dalam memanfaatkan dan menyalurkan penggunaan ilmu pengetahuan dan teknologi.

4. Penyuluhan motivasi usaha dan pelatihan manajemen usaha memberikan pengetahuan dan pemahaman dari kelompok ternak lele yang ada di Jatisari agar selalu siap menghadapi persaingan dunia usaha, komitmen selalu berkembang dan inovasi. Selain itu juga selalu memperbaiki kegiatan produksi, menggunakan jaringan pemasaran, dan juga selalu mencatat setiap transaksi dari kegiatan usaha melalui catatan pembukuan agar dapat diketahui perkembangan usahanya.

\section{Saran}

Program ini sangat dibutuhkan oleh perguruan tinggi, khususnya dosen dalam melakukan pengabdian masyarakat dan juga dibutuhkan masyarakat dalam membantu memberikan solusi dari permasalahan yang masyarakat hadapi. Harapan dari tim pengabdian masyarakat, pendanaan dapat lebih ditingkatkan dan tidak terlambat dalam pencairan karena bagi PTS binaan menjadi penyokong dana terlebih dulu kadang belum bisa dilakukan $100 \%$ karena PTS dana juga terbatas.

\section{DAFTAR PUSTAKA}

Adi, I.R, 2002, Pemikiran-pemikiran dalam Pembangunan Kesejahteraan Sosial. Jakarta Lembaga Penerbit FE-UI

Azis A.D. Alamsyah dkk, 2013, "Prosiding SNST ke-4 Tahun 2013 Fakultas Teknik Universitas Wahid Hasyim Semarang, ISBN 978-602-99334-2-0

Ditjen DIKTI, 2013, Panduan Pelaksanaan Penelitian dan Pengabdian Kepada Masyarakat di Perguruan Tinggi, Edisi IX.

Ditjen DIKTI, 2016, Panduan Pelaksanaan Penelitian dan Pengabdian Kepada Masyarakat di Perguruan Tinggi, Edisi X

Kadek H., M.Ariza Y, 2015, "Pembuatan Pakan Lele Di Usaha Kecil Menengah Budidaya Ikan Lele Di Desa Marga Agung Kecamatan Jati Agung Kabupaten Lampung Selatan “, Jurnal Pengabdian Kepada Masyarakat, Vol. 01, No.1, Februari 2015.

www.bumn.go.id/perikananindonesia/berita/111/Dosen Universitas Negeri Solo Sulap Kotoran Unggas Jadi Pakan Ikan

http://www.suaramerdeka.com/v1/index.php/read/news_solo/2013/10/07/174776/DosenUNS-Sulap-Kotoran-Unggas-Jadi-Pakan-Ikan- 
p ISSN: 1410-9344, e ISSN: 2549-5631

http://www.tempo.co/read/news/2013/10/04/061518988/UNS-Kembangkan-Pakan-Lele-dariKotoran-Puyuh 